Available online at http://docs.lib.purdue.edu/jate

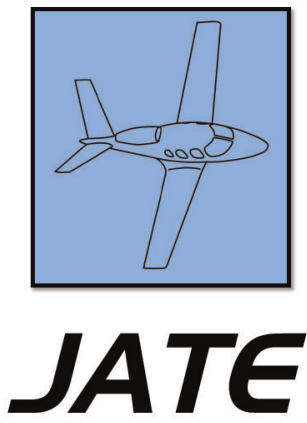

Journal of Aviation Technology and Engineering 6:1 (2016) 34-43

\title{
Designing Fixed-Base Operations Utilizing Systems Engineering Principles
}

\author{
Ross L. Stephenson Jr. and David A. Carroll \\ Embry-Riddle Aeronautical University Worldwide
}

\begin{abstract}
There are currently over 3,200 fixed-base operations (FBOs) conducting business in the United States attempting to meet the demands of FAA Part 91, Part 135, and a limited number of Part 121 operations. With the US economy slowly climbing out of the trough during 2013, the utilization of fixed-base operations has become more attractive and economical to the corporate business and the affluent recreational traveler. Despite the increased flight activities utilizing the services of fixed-base operators, keen competition, rising fuel cost, and the economies of scale recognized by large FBO franchises significantly erode the profitability and sustainability of smaller FBOs. The goal of the current paper is to describe the major systems inherent in fixed-base operations design and apply systems engineering principles to develop and document a set of requirements and identify the relevant technical components that are needed to maintain a sustainable fixed-base operation. Requirements from the industry should be met by a customer-oriented, environmentally friendly operation that meets the ever-changing demands of clientele and the market. Future design work will build on the proposed preliminary architecture to satisfy these requirements.
\end{abstract}

Keywords: systems engineering, fixed-base operations, design, SPADE

\section{Introduction}

All too often the basic business model of the typical fixed-base operator (FBO) has been a simple one: increase your markup on your fuel sales to cover all your expenses (Enticknap \& Jackson, 2012). During the past decade, recession conditions experienced in the United States economy, rising fuel costs, and unfortunate political comments have damaged the image of corporate business travel (Enticknap \& Jackson, 2012). The fallout of these events has seriously degraded the profitability of the FBO. Activity from domestic operations increased by 2.4 percent in 2013, with Part 135 operations increasing by 11.3 percent, indicating the US economy has tentatively begun its climb out of the trough (Epstein, 2014). However, with fuel sales increasing, and further consolidation of the FBO industry, smaller non-franchised FBOs must increase streamlining and efficiency in their business practices in order to sustain profitability, let alone existence (Hodges, 2008).

\section{Background}

The FBO provides a number of essential services primarily to general aviation aircraft operators. FBOs must operate under a lease with its resident airport and offer Jet A and/or Avgas (NATA, 2009). Typically, the "FBO must perform at 
least one of four other basic services: line service, which may include tie-down and hangar services; technical services, such as airframe and engine maintenance; aircraft rentals, charters, aircraft management, and/or aircraft sales; and flight instruction" (NATA, 2009, p. 10). Prior to the passage of the Air Commerce Act of 1926, most aviation operations were unregulated, with transient pilots, or barnstormers, flying surplus World War I aircraft from town to town and setting up shop wherever they could (Lynch, 2012). Aviation operations became more popular and widespread, requiring that facilities of a more permanent nature be established to provide services to resident and transient aircraft operators. The first FBOs began as early as 1914 (Lynch, 2012). Today, FBOs must meet specific requirements to provide the public reasonable and safe services without unjust discrimination (FAA, 2006).

\section{Scope}

This paper will examine the design of a typical FBO in aviation through the use of systems engineering principles using the System Decision Process (Parnell, Driscoll, \& Henderson, 2011). The team will define the problem by determining stakeholder and client needs and expectations, and by identifying the major risks. This analysis will focus on the broad spectrum of FBO types, and as such will not include every service found at every FBO. Uniformly, FBOs provide such services and products as ramp servicing, aircraft fuel, aircraft maintenance, and aircraft storage.
The problem under examination is bounded by the aforementioned services. In essence, the boundaries contain all the services an FBO provides that directly support the pilot's flying operations. FBO operation and/or ownership of an airport will not be considered, nor will ground side services such as a rental car concessions, restaurants, and pilot shops. Flight training and aircraft rental, while often found at an FBO, will also not be considered, as they do not contribute directly to flight operations. While many FBOs may include these other services, they are excluded to make this analysis universally applicable.

\section{Systems Engineering and Design Framework}

Management of fixed-base operations relies upon the successful integration of systems engineering principles. FBO managers must continually define the ever-changing needs of their dynamic clientele in order to design and enable their service systems to meet the needs of their customers. These systems vary in nature and life cycle, as do the needs of the aviation industry. Shainee et al. (2012) framework for conceptual designing that incorporates social, technical, and environmental principles will be used in the design process, and is shown in Figure 1.

Environmental circumstances, aviation industry trends and practices, and general economic conditions to include scheduling and budget constraints can affect how FBO managers address the everyday practice of problem solving and the effectiveness of their actions. However, utilizing a systems

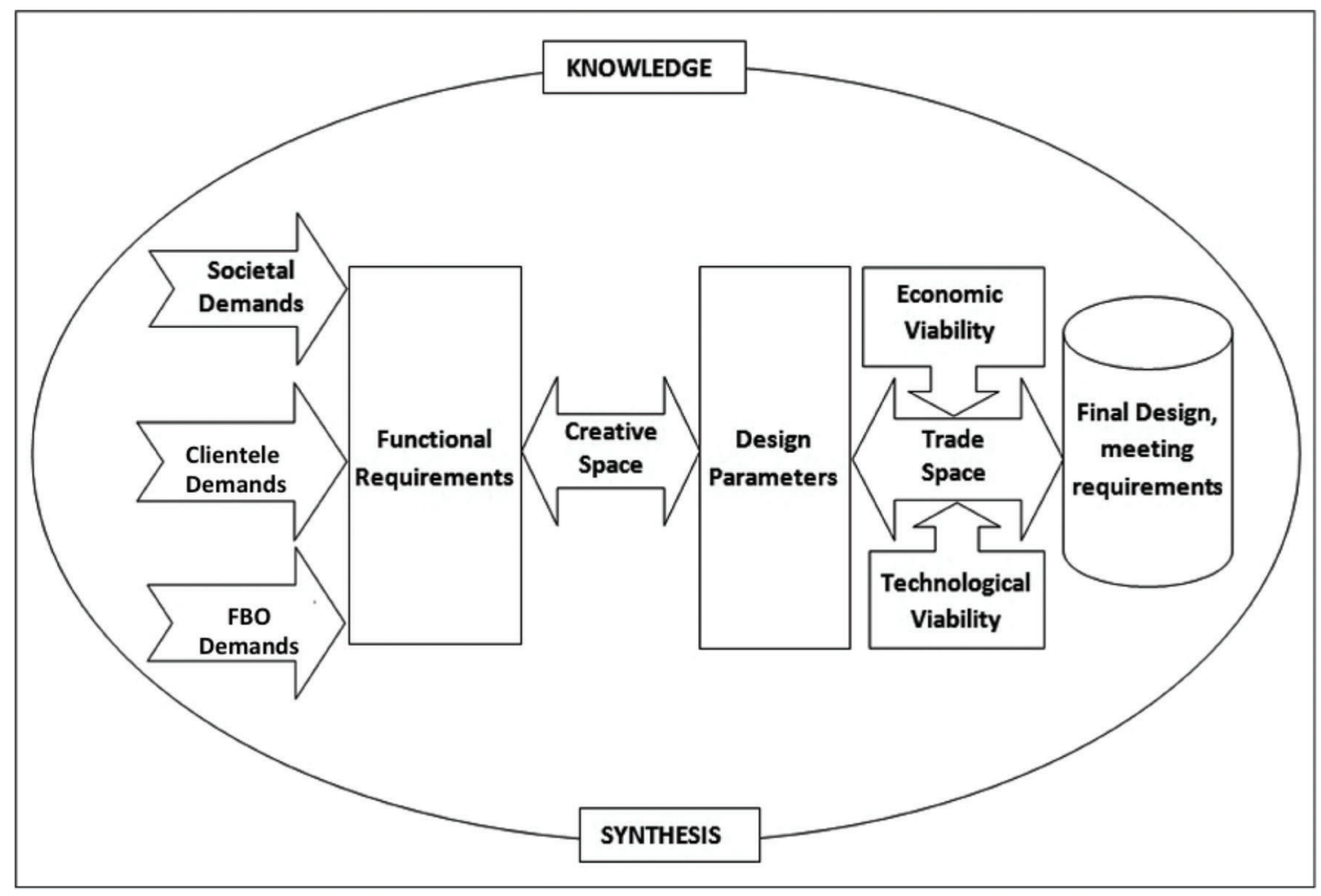

Figure 1. Framework for conceptual designing of systems (modified after Shainee, Haskins, Ellingsen, \& Leira, 2012). 
engineering approach to frame daily routine activities at the FBO will increase efficiency by minimizing associated resources, and therefore maximizing profit margins by activity (Press, 2001). In addition, utilizing systems engineering concepts will enhance control and continuity, which will improve FBO sustainability (Press, 2001).

Systems engineering principles as applied to aviation industry business services can be thought of as a market proposition that extends the traditional functionality of a product design systems engineering concept to that of incorporating the same systems engineering principles during the development of services (Baines et al., 2007). In this case, the customer is purchasing a value-added service as opposed to a product that may be delivered. This service is more than merely payment for performance, where the provider is offering the client an essential good or artifact (Spohrer \& Maglio, 2008). This servitization provides a value-added benefit to the client in the fact that the delivery of the service lacks the traditional risks, responsibilities, and financial obligations typically associated with the purchase of a product (Baines et al., 2007). The end state is an FBO that provides an integrated product and service offering that renders value in its use while achieving system sustainability (Baines et al., 2007). Customer satisfaction and economic viability are key elements for sustainability (Baines et al., 2007). The authors will use the simplified framework of reformulated systems engineering principles know as SPADE as introduced by Haskins (2008). The SPADE methodology addresses the identity and requirements of the stakeholders, frames the problem, develops alternatives, chooses a course of action, and evaluates the outcome of activities continuously (Shainee et al., 2012). A graphical depiction of the SPADE methodology/framework is shown in Figure 2. The methodology is also referred to as a framework to reflect its ability to provide a structure for the analysis of activities (Haskins, 2008, p. 27). The SPADE framework will provide structure for the analysis of the business activities that occur at an FBO.

Haskins's SPADE framework is unique in its non-linear depiction of the problem-solving process. While entry to the framework may be made at any point, Haskins recommends determining Stakeholder needs to improve success (Haskins, 2008). Another unique feature of the SPADE model is that movement within the model may proceed in any direc- tion, to include into or across the center. The SPADE representation of the systems engineering process replaces the typical (and visually complicated) linear representation with multiple feedback loops and replaces it with the circular representation that allows free movement within the model to facilitate feedback to any step (Haskins, 2008).

\section{Problem Formulation}

While this paper will examine the FBO as a complete system, the authors will specifically address two subsystems of the FBO: the refueling operations subsystem and the maintenance subsystem.

Delivery of FBO services for general aviation private and business travelers has accelerated with ever increasing complexity as the US economy rebounds. The FBO industry was forecasted to grow at a rate of 4-6\% in 2013 with further gains in 2014 (Enticknap \& Jackson, 2013). The aviation economy is slowly recovering, as indicated by increases in reported hours flown by corporate and charter operations, increases in the sale of new business aircraft, and decreases in inventories of used aircraft (Enticknap \& Jackson, 2013). But increased fuel costs have caused aircraft operators to change how they manage their fuel costs. Aircraft operators now often purchase fuel at predetermined locations where they have secured an excellent price by purchasing in quantity, and often fill the aircraft as full as possible at these locations (called "tankering") to take full advantage of the reduced price (Enticknap \& Jackson, 2013). These changes in how FBO clients operate from a fuel standpoint have increased the operational demands on the FBO service provider requiring more efficient means of doing business.

The majority of the FBO's income originates from flight line activities, specifically fuel sales. Fuel margins of $\$ 2$ per gallon of Jet A have been typical in previous years, but growing competition has driven the average margin to below $\$ 1.60$ per gallon (Moore, 2014). More efficient aircraft and the practice of fuel tankering also further reduce the total fuel sales in some cases and exacerbate the problem. "Tankering, the purchase of fuel in excess of that immediately required for the next flight leg, simply means topping off the tanks at the cheaper stations to the extent

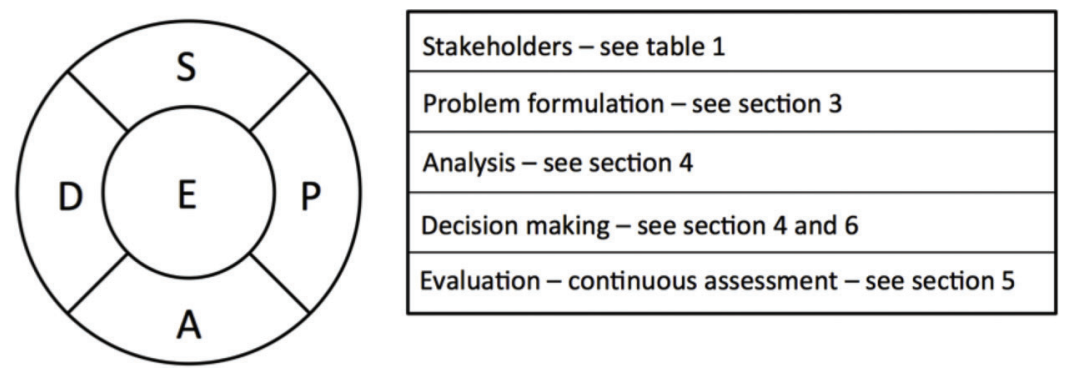

Figure 2. SPADE systems engineering framework (Haskins, 2008). 
the increased burn penalty and station supply allow" (Nash, 1981). Fuel tankering would be very much like the dollar cost averaging technique used with purchasing non-perishable commodities.

The market wholesale price for fuel paid by FBO owners does not vary significantly from region to region. Retail fuel cost variations encountered by general aviation clientele would be associated with specific cost to build, operate, and maintain fuel containment and disbursement facilities at individual FBOs and the additional retail markups necessary to finance less profitable services offered by the FBO (Hodges, 2008). The typical practice of using exorbitant markup pricing on fuel sales to finance less than profitable services by the FBO has the possibility of sending FBO customers elsewhere in search of more reasonable fuel prices or purchasing the minimum fuel required to fly to their follow on destination safely (Hodges, 2008). By applying systems engineering principles to the primary functions of the FBO, services may be provided to the customer and community at more reasonable prices while maintaining adequate operational profit margins.

Another service normally provided by the FBO is aircraft maintenance. While some FBOs provide only minor repairs and maintenance required to get a customer's aircraft back in the air after some malfunction en-route, others offer a full range of minor and major repairs, alterations, inspections, and such. One element in deciding what type of service to provide is the level of service required by the airport's operating authority. For example, FBOs operating on airports owned by the Commonwealth of Pennsylvania (1997) are required to provide "comprehensive maintenance services" for airframes, powerplants, and accessories. In addition, the Federal Aviation Administration (FAA) stringently regulates the provision of aircraft maintenance. 14 CFR Part 145, Repair Stations, clearly delineates the requirements to provide aircraft maintenance services (FAA, 2001). The company requires licensure by the FAA, as do the employees working on the aircraft and its components. Tools, highly specialized equipment, and parts and materials are required. While the FAA defines what is required, it does not often specify how to meet the requirements. The application of systems engineering principles to this subsystem of FBO operations can create an efficient and profitable maintenance operation.

\section{Analysis of the Problem}

The identification of the stakeholders is crucial to constructing a successful system design (Shainee et al., 2012). While typically this would involve an experienced engineer, consultation with a knowledgeable aviation industry professional such as the FBO manager will ensure that all the primary and secondary stakeholders and their requirements upon the system are identified Stakeholders, and will assert various demands upon components of the system or on the complete system, which will influence the resultant design (Shainee et al., 2012). Table 1 identifies the primary and secondary stakeholders and their requirements upon the FBO.

Review of the source documents identified five primary stakeholders and four secondary stakeholders and their requirements. The secondary stakeholders provide aviation industry-specific market guidance and government regulatory direction on the execution of the activities of the FBO that indirectly complement or hinder the fulfillment of the requirements of the primary stakeholders (Shainee et al., 2012). It would be negligent to discount contributions and influences of the secondary stakeholders during the design process.

A thorough literature review was conducted to identify aviation industry-specific business related system characteristics required for successful and sustainable FBO operations. Three source documents provided specific regulatory guidance and the most current forecasted market requirements

Table 1

Stakeholders and their needs.

\begin{tabular}{|c|c|}
\hline Primary Stakeholders & Requirements \\
\hline Consumer & High quality product; Affordable product; Timely service. \\
\hline Environment & $\begin{array}{l}\text { Minimum impact to and from adjacent biological and physical environment; } \\
\text { Minimum impact to and from adjoining industries and services; } \\
\text { Minimum impact to adjacent residential communities. }\end{array}$ \\
\hline FBO Manager & $\begin{array}{l}\text { Technologically sustainable; Economically sustainable; } \\
\text { Capability to adapt to customer needs and preferences. }\end{array}$ \\
\hline $\begin{array}{l}\text { Employees } \\
\text { Airport }\end{array}$ & $\begin{array}{l}\text { Training and development; Communication Health and safety; Pay and benefits. } \\
\text { Maximum utility in tenant supporting operations; Maximum safety standards. }\end{array}$ \\
\hline Secondary Stakeholders & Contributions \\
\hline Manufacturers & $\begin{array}{l}\text { Provide restrictions and advice on available components of FBO, such as fuel trucks, } \\
\text { aircraft tug, component work stands, etc. }\end{array}$ \\
\hline Suppliers & $\begin{array}{l}\text { Advice on the ability to supply equipment and components to specific FBO location based } \\
\text { on the requirements of the primary stakeholders. }\end{array}$ \\
\hline Government Authorities & Restrictions and conditions on design and operation. \\
\hline Financial Institutions & Provide available funds for operations and improvement. \\
\hline
\end{tabular}


and demands associated with FBO operations and were selected as primary source documents. The incorporated characteristics of our model FBO design are contained within the primary source documents. The three source documents are:

SD1. Minimum standards for fixed-base operations at commonwealth-owned airports (Pennsylvania Department of Transportation, 1997).

SD2. National Air Transportation Association (NATA) prospective analysis of the aviation sector in the United States (NATA, 2009).

SD3. US Bureau of Labor Statistics prospective analysis of the aviation sector in the United States (Bureau of Labor Statistics, 2014).

The first source document (SD1) covers the operational, environmental, economic, and safety-related aspects of FBO operations defined by Pennsylvania's Department of Transportation. Aviation industry regulations regarding the conduct of commercial aviation activities are defined in FAA Advisory Circular No. 150/5190-7 (FAA, 2006). These regulations specifically address minimum standards for the conduct of commercial aeronautical activities and are incorporated in the directives of SD1. A review of other state government-directed minimum operational requirements for fixed-base operations was conducted and it was concluded that SD1 was representative of governmentdirected minimum requirements. The second document (SD2) is published by NATA. NATA is a public policy group that represents the interests of the general aviation business community before Congress and federal, state, and local government agencies, providing a broad range of services to general aviation, the airlines, and the military (NATA, 2009). NATA has always been the advocate for smaller, single location FBOs that depend exclusively on general aviation for their livelihood (NATA, 2009). SD2 provides NATA's prospective analysis of the aviation industry sector in the United States and specifically addresses FBO operations (NATA, 2009). The third source document (SD3) contains information relating to employment in the air transportation industry as presented by the US Department of Labor's Bureau of Labor Statistics (BLS) (2014). All the data presented within the BLS regarding the aviation industry is obtained from employer or establishment surveys (BLS, 2014). The prospective analysis in SD3 presents an overview of the industry including the number of jobs, data for occupations common to the industry, and projections of occupational employment change.

The third source document (SD3) provides the Bureau of Labor Statistics prospective analysis and economic outlook for the aviation industry. Specific labor skill sets within the aviation industry are identified along with current labor demands and forecasted growth. Specific labor wage rates as provided within SD3 will be essential in defining market wage rates within FBO system components.

\section{Measures of Effectiveness}

Measures of effectiveness (MOEs) will provide a means for which to gauge the viability and success rate of identified alternatives, and more importantly, MOEs should be consistently referenced during the system design process (Sproles, 2002). Analysis of primary and secondary stakeholder requirements and values will be essential in formulation of reliable measures of effectiveness (Parnell et al., 2011).

The designer of the component systems and FBO system as a whole must have access to stakeholder details in order to determine what the component systems and subsystems must achieve in order to satisfy the needs and requirements of the stakeholders (Sproles, 2002). The source documents presented above and the stakeholder requirements listed in Table 1 provide the reference data for the formulation of the FBO MOEs. The MOEs are as follows:

1. The designs shall conform to all regulatory directives concerning employee and clientele safety and welfare during the routine performance of services.

2. The designs shall not compromise performance of other normal services due to the rendering of routine aircraft ramp operations.

3. The designs shall provide economically feasible services to all clientele.

4. The designs shall conform to all regulatory directives concerning environmental safety.

5. The designs shall incorporate the state-of-the-art techniques and material for all services.

\section{Information Models}

Information models were created to provide abstract representation of the system activities and collaborative behavior involved during FBO operations. These models assist in describing the system and subsystem component operations within the FBO and the associated interaction of stakeholders (Shainee et al., 2012).

Decomposition of source documents to system functions and components is illustrated with the requirement traceability information model illustrated in Figure 3 (Shainee et al., 2012). This model provides a hierarchical view of the functions and components of the FBO. Two functions are designed from reference to the source documents. Function 1 (F1) defines the general aviation services that the FBO must provide at a specific geographic location. Function 2 (F2) defines the general aviation market business services that the FBO must provide in order to meet the market demands as indicated in SD2 and SD3.

System functions are allocated to individual system components. In this requirements traceability information model as represented in Figure 4, the specific components allocated from $\mathrm{F} 1$ are unique to the specifications listed in SD1. 


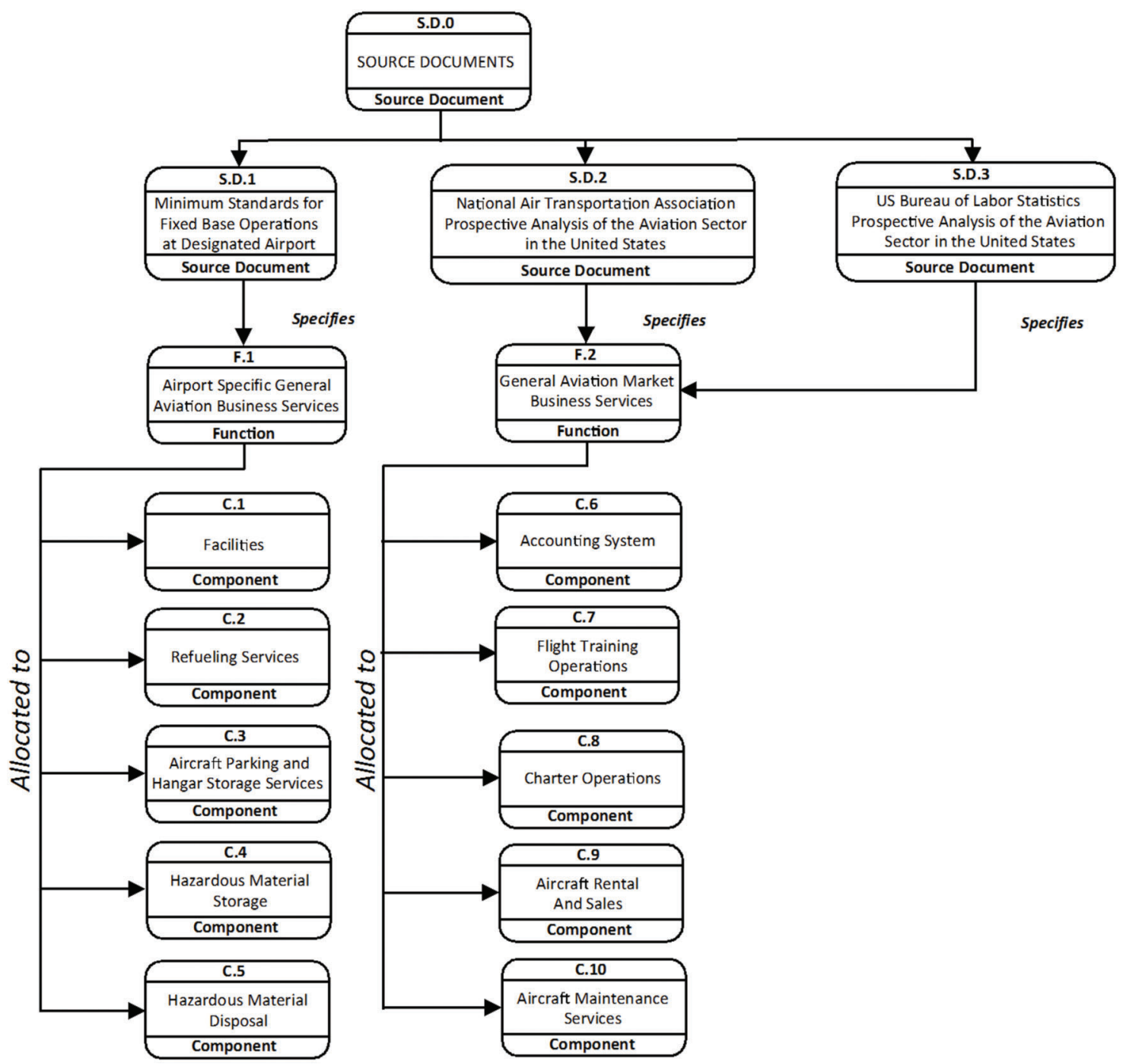

Figure 3. Requirements traceability information model. Adapted from "Designing Offshore Fish Cages Using Systems Engineering Principles" by Mohamed Shainee, Cecilia Haskins, Harald Ellingsen, and Bernt J. Leira (2012), Systems Engineering, 15(4), 402.

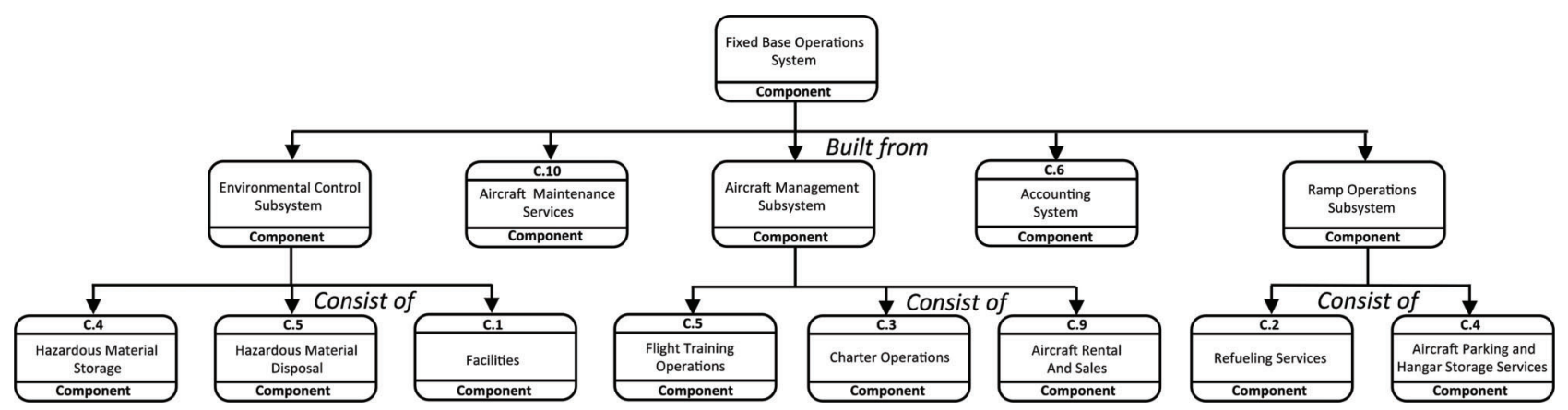

Figure 4. Architectural information model. Adapted from "Designing Offshore Fish Cages Using Systems Engineering Principles" by Mohamed Shainee, Cecilia Haskins, Harald Ellingsen, and Bernt J. Leira (2012), Systems Engineering, 15(4), 402.

However, the specific components allocated from F2, while not specifically listed as requirements in SD1, are often listed as requirements at some FBOs. Nevertheless, this model illustrates an FBO that meets the requirements of commonwealth-owned airports in the state of Pennsylvania and meets the overall market demands for the aviation industry in the United States. It should be noted that while all FBOs do not have the component of flight training operations (C7), all FBOs have a defined accounting system (C6). In this particular model, SD1 did not specify an accounting system component requirement. Attention is given to this aspect of the model because components 
allocated from one or more functions may be the same. For instance, some states or local municipalities may list specific directions on the component requirement for an accounting system. This is brought up to illustrate the cross-functionality of the components, whereas the component need not be listed twice in the model.

An architectural information model is used to illustrate how system components are interrelated and how they work together with other components and subsystems (Shainee et al., 2012). The components allocated from the functions in the requirement traceability information model (see Figure 4) are used to construct this model. The Environment Control Subsystem, the Aircraft Management Subsystem, and the Ramp Operations Subsystem are introduced in the architectural information model providing a hierarchal abstract of command and control; some other word for the components within that subsystem.

\section{Refueling Workflow Model}

Ramp operations, specifically refueling activities, account for the majority of business services offered by the FBO. The refueling workflow information model in Figure 5 depicts the activities that occur within the conceptual framework of the refueling of transient and resident aircraft. This framework consists of a systematic requirements satisfaction process where specific stakeholders' needs and requirements are satisfied by the design process (Shainee et al., 2012).

A key element of this model is that it leverages the investment made in information technology (IT) systems to maximize operational efficiency of the refueling process. The complex environment of the FBO aircraft ramp can be influenced by a myriad of factors that can affect the overall operational efficiency of the refueling process (Banker, Kauffman, \& Morey, 1990). Banker and colleagues (1990) remark that utilizing IT systems minimizes the possibility of "random" (p. 32) inefficiency that can occur during operations. The magnitude of the element of random inefficiency, identified as a variable in the refueling process, is affected by the management and execution of the operation (Banker et al., 1990). However, due to the uncertainty of the origin and timing of the random inefficiency variable, its value cannot be directly measured.

The conceptual refueling workflow model provides a systems engineering approach to the activity of refueling

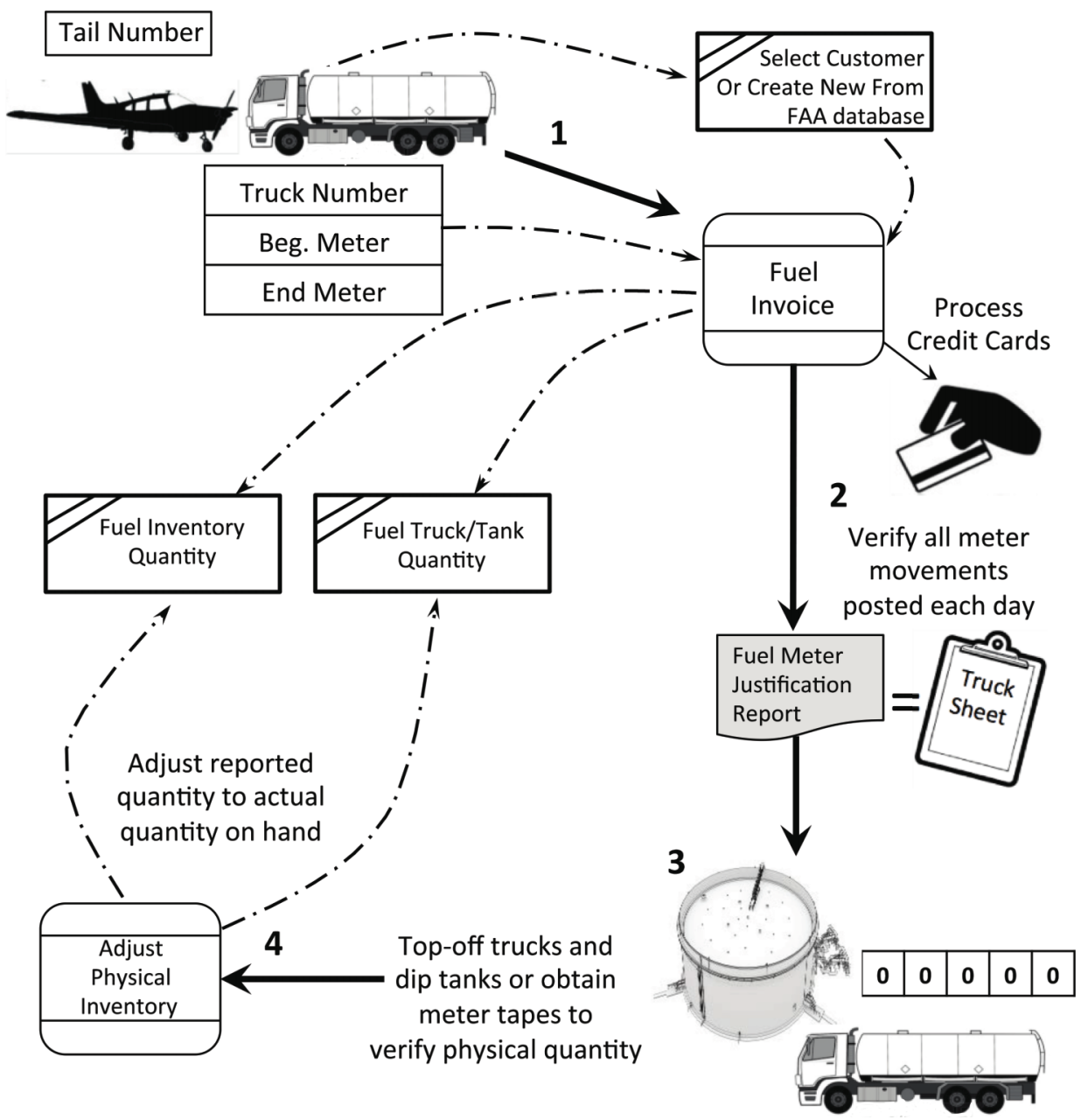

Figure 5. Refueling workflow information model. Adapted from "TotalFBO Users Guide” by Horizon Business Concepts, Inc. (2008). 
aircraft while maintaining accurate verification of fuel inventories. Utilizing IT systems during the refueling process minimizes the occurrence of the random inefficiency variable, thus increasing efficiency. This initial design is considered the best viable option until further improvements are recognized during the ongoing evaluation phase.

\section{Maintenance Workflow Model}

Aircraft maintenance activities can be a very lucrative revenue stream for an FBO. These services, however, are highly regulated by the FAA. The FBO must employ properly licensed mechanics and inspectors, and may have to have a repair station license itself. The mechanics and inspectors must have current technical manuals for every type of aircraft they service. Parts and materials must come from authorized sources. The facility must possess the necessary tooling and equipment to properly maintain aircraft. All of this regulatory background serves to lay the foundation that allows aircraft maintenance activities to be legally performed.

With the necessary foundation in place, maintenance services follow the maintenance workflow information model depicted in Figure 6. The process includes customer approval and acceptance steps to ensure satisfaction of these critical stakeholders. A promising source of improvement is utilizing IT to facilitate many of the activities that must currently be done manually, and in reducing the number of hardcopy manuals, parts catalogs, and other documents that require page-change revisions with digital versions that are updated automatically and constantly. Using IT to track labor, parts, and materials simplifies accounting as well as increases accuracy of inventories.

By assigning each mechanic an iPad-like device, the FBO can track the status of each aircraft for maintenance. As work is evaluated, the mechanic can add pictures to the work order to show the exact problem and document the repair. Parts can be ordered right from the aircraft. Customer billing records can also be automatically updated and computed. A major benefit from such a system is the sharing of information between functions. Manual tracking and documenting systems often require transcription of information from the aircraft maintenance logs, to the work order, to the mechanic's work cards. Having the discrepancies entered directly into the system, and then immediately shared, eliminates transcription errors (Gamauf, 2012). Another benefit of having the technology available to the mechanic at the aircraft is the elimination of a significant amount of "travel time." With the information at the aircraft, the mechanic does not have to stop working, walk to where the manuals are located to look up procedures or find part numbers to be ordered, and return to resume working. This saves a significant amount of time in an average day. By including IT in the design of the maintenance workflow from the beginning, the benefits of using this technology can be maximized. Once again, this initial design will be reviewed and improved within the ongoing evaluation phase.

\section{Evaluation}

Evaluation is continuous, with an iterative cycle of operations and evaluation. After initial deployment, the process must stabilize to facilitate the necessary measurement and analysis (Pall, 1987). Only through stabilizing and standardizing the process can wasteful practices be detected and eliminated. The new process becomes the standard, which is again evaluated to find wasteful and inefficient practices. This iterative process is continuously repeated to ensure that the system continues to operate as efficiently as possible, even as changes occur in the operating environment (Liker, 2004). Along with identifying wasteful practices, FBO performance will be evaluated against the MOEs identified above. An efficient system with minimum waste that fails to meet shareholders needs is not an effective system.

\section{Implementation}

Implementation of systems engineering principles by FBO managers facilitates the efficient means of delivering valueadded service to their customers while maintaining optimum profit margins (Spohrer \& Maglio, 2008). FBO managers begin this crucial process by identifying their stakeholders' needs and expectations to design the supporting service systems. These needs and expectations are dynamic and should be continuously assessed in order to directly support the customer's flight operations (Baines et al., 2007). Regardless of whether the FBO employs a phased approach to implementation (likely for an existing operation), or an all-at-once approach (appropriate for a new operation), meeting the needs of the stakeholders must be foremost in establishing the system.

Daily routine practices of the FBO should be conducted within the regulatory constraints of its specific operations. In order to do so, FBO managers must identify the environmental, economic, and aviation industry factors that affect everyday processes. Analysis of these factors and associated effects on daily processes will allow the FBO manager to implement the necessary risk mitigation measures to these processes (Haskins, 2008).

Evaluation of process effectiveness should be a neverending task of the FBO manager. In order to maximize the value-added benefits to its customers, the effectiveness of every process within the FBO must be monitored and evaluated against defined standards (Parnell et al., 2011; Sproles, 2002). This constant process of evaluation will facilitate the FBO manager's efforts to maximize customer satisfaction, thus fostering the sustainability of the FBO (Baines et al., 2007). 


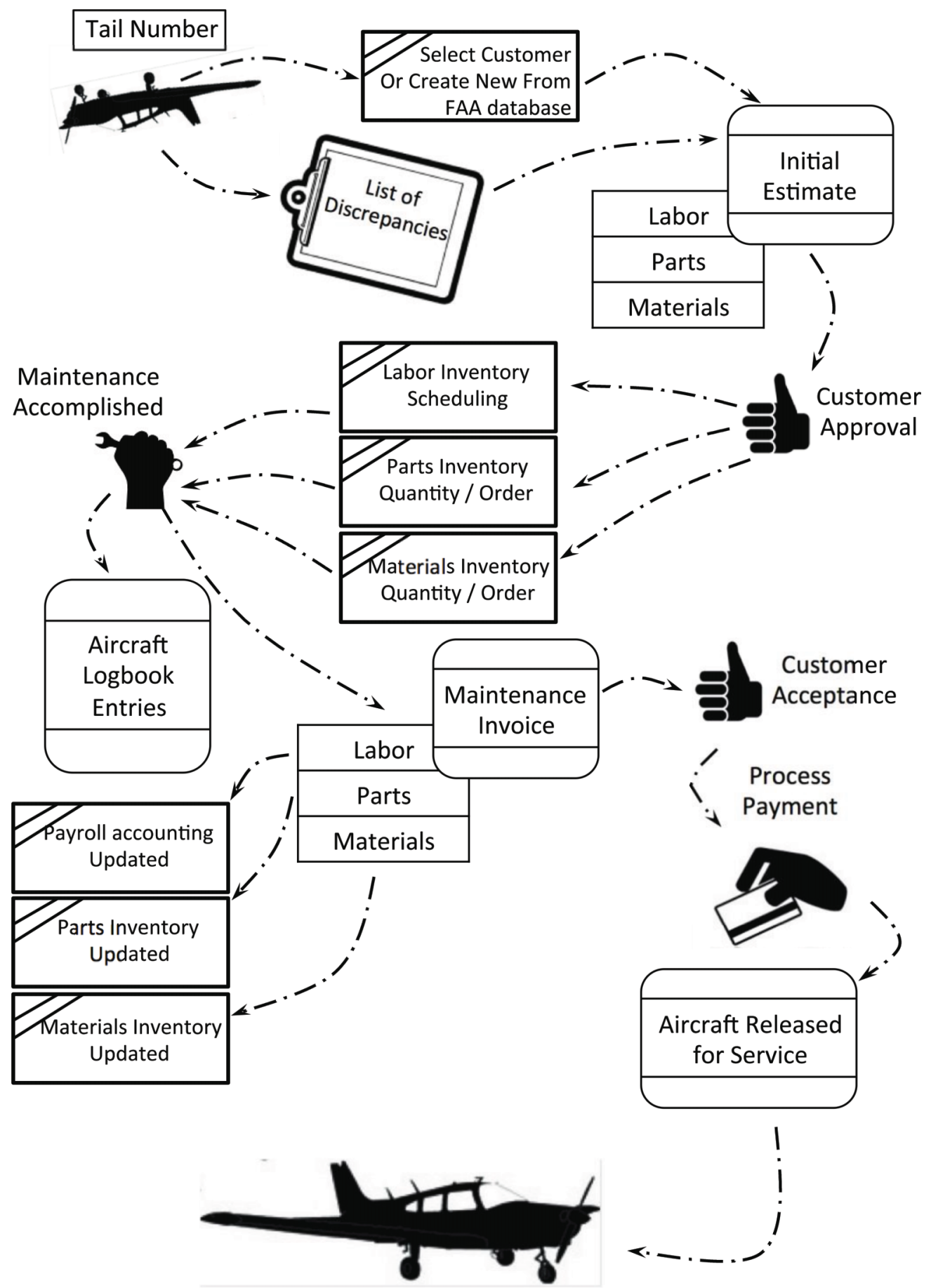

Figure 6. Maintenance workflow information model. Adapted from "TotalFBO Users Guide” by Horizon Business Concepts, Inc. (2008).

\section{Conclusion}

FBO operational efficiency and market competitiveness can be enhanced through the application of systems engineering principles. Through the use of the SPADE framework, a systematic approach was used to identify the stakeholders and their needs, and to define and analyze the problem. Further, MOEs were developed to assess the specific processes of refueling and maintenance operations as illustrated by conceptual models. By using systems engineering principles in the design of FBOs, business owners and managers can improve the degree of sustainable efficiency in operations while simultaneously maximizing the positive and minimizing the negative effects on the economic, social, and environmental facets of their operations (Haskins, 2008).

Advanced IT applications have tremendous promise in increasing the efficiency, and thus profitability, of FBOs. Data-connected ramp agents, fuel trucks, mechanics, and 
inspectors can all feed information into the accounting network with greater accuracy in less time. Further, a fully IT-integrated business process facilitates more accurate analysis of the process, leading to more focused improvements and a more efficient and profitable process. With the oft razor-thin margins with which many FBOs operate, every increase in efficiency can yield significant results at the bottom line. Designing a FBO with fully IT-integrated processes and subprocesses may provide the business that undertakes the challenge with an efficiency advantage that will allow it to cruise through economic headwinds, and soar during bright economic times.

Designing an FBO from scratch, using systems engineering principles, to meet carefully defined stakeholder expectations, may hold the keys to maximizing FBO profitability. By leveraging advanced wireless information technology, designed in from the start rather than added as an afterthought, errors can be minimized while simultaneously increasing speed and automating a significant number of tasks. The stakeholder focus provided by a system engineering approach has the best likelihood of achieving these goals.

\section{References}

Baines, T. S., Lightfoot, H. W., Evans, S., Neely, A., Greenough, R., Peppard, J., Wilson, H. (2007). State-of-the-art in product-service systems. Proceedings of the Institution of Mechanical Engineers, 221(B10), 1543-1552. Retrieved from http://dx.doi.org/10.1243/ 09544054JEM858

Banker, R. D., Kauffman, R. J., \& Morey, R. C. (1990). Measuring gains in operational efficiency from information technology: A study of the positran deployment at Hardee's Inc. Journal of Management Information Systems, 7(2), 29-54. Retrieved from http://search. ebscohost.com $/ \operatorname{login}$. asp $x$ ?direct $=$ true $\& d b=b$ th $\& A N=5748103 \&$ site $=$ ehost-live

Commonwealth of Pennsylvania. (1997). Title 67 Pennsylvania Code § 476, Minimum standards for conducting fixed base operations at commonwealth-owned airports. Retrieved from http://www.pacode. com/secure/data/067/chapter476/067_0476.pdf

Enticknap, J. L., \& Jackson, R. R.. (2012). A changing FBO business model- "You can't give it away." Retrieved from http://nata.aero/ data/files/safety\%201st\%20documents/etoolkit/safety\%201st\%20etool kit\%20october2012.pdf

Enticknap, J. L., \& Jackson, R. R. (2013). FBOs to compete on service, not price in 2013-Steady 6\% growth forecast for FBOs. Retrieved from http://nata.aero/data/files/safety\%201st\%20documents/etoolkit/safety\% 201st\%20etoolkit\%20februarymarch2013.pdf

Epstein, C. (2014). AIN FBO survey 2014: The Americas. Aviation International News, 46(4).

Gamauf, M. (2012). iPads in the hangar. Business \& Commercial Aviation, $108(4), 38$.

Haskins, C. (2008). Systems engineering analyzed, synthesized, and applied to sustainable industrial park development (Doctoral dissertation). Fakultet for samfunnsvitenskap og teknologiledelse.

Hodges, M. A. (2008). Reconsidering how FBOs operate. Airport Business, 22, 20-22. Retrieved from http://search.proquest.com.ezproxy.libproxy. db.erau.edu/docview/198860944?accountid $=27203$

Horizon Business Concepts, Inc. (2008). TotalFBO users guide. Toronto, ON: Webcom Limited.

Liker, J. K. (2004). The Toyota way: 14 management principles from the world's greatest manufacturer. New York: McGraw-Hill.
Lynch, J. (2012). The FBO business. Retrieved from http://www.get-aviation. com/blog/aviation-thoughts/the-fbo-business-written-by-joseph-lynch

Moore, J. (2014). FBOs in a bind: No more freebies? Retrieved from http://www. aopa.org/News-and-Video/All-News/2014/January/30/fbos-in-a-bind.aspx

Nash, B. (1981). A simplified alternative to current airline fuel allocation models. Interfaces, 11(1), 1-9.

National Air Transportation Association (NATA). (2009). National air transportation association factbook. General aviation in the United States. Retrieved from http://www.castleair.com/wp-content/uploads/ 2014/05/NATA_factbook.pdf

Pall, G. A. (1987). Quality management. Upper Saddle River, NJ: Prentice Hall. Parnell, G. S., Driscoll, P. J., \& Henderson, D. L. (2011). Decision making in systems engineering and management. Hoboken, NJ: John Wiley \& Sons.

Press, D. A. (2001). Systems engineering fundamentals. Defense Systems Management College Press, Fort Belvoir, Virginia. Retrieved from https://ocw.mit.edu/courses/aeronautics-and-astronautics/16-885jaircraft-systems-engineering-fall-2005/readings/sefguide_01_01.pdf

Shainee, M., Haskins, C., Ellingsen, H., \& Leira, B. J. (2012). Designing offshore fish cages using systems engineering principles. Systems Engineering, 15(4), 396-406. http://dx.doi.org/10.1002/sys.21200

Spohrer, J., \& Maglio, P. P. (2008). The emergence of service science: Toward systematic service innovations to accelerate co-creation of value. Production and Operations Management, 17(3), 238-246. Retrieved from http://search.proquest.com.ezproxy.libproxy.db.erau.edu/docview/ 228750858? accountid $=27203$

Sproles, N. (2002). Formulating measures of effectiveness. Systems Engineering, 5(4), 253-263. http://dx.doi.org/10.1002/sys.10028

United States Department of Labor, Bureau of Labor Statistics (BLS). (2014). Industries at a glance: Air transportation: NAICS 481. Retrieved from http://www.bls.gov/iag/tgs/iag481.htm

United States Department of Transportation, Federal Aviation Administration (FAA). (2006). Minimum standards for commercial aeronautical activities. AC No: 150/5190-7. Washington, DC. US Government Printing Office. Retrieved from http://www.faa.gov/documentLibrary/media/ advisory_circular/150-5190-7/150_5190_7.pdf

United States Department of Transportation, Federal Aviation Administration (FAA). (2001). 14 CFR Part 145-Repair stations. Washington, DC. US Government Printing Office. Retrieved from http://www.ecfr.gov/ cgi-bin/text-idx ?SID $=580370 \mathrm{~d} 90 \mathrm{c} 9 \mathrm{e} 0 \mathrm{~d} 119 \mathrm{f} 230 \mathrm{de} 3086 \mathrm{a} 6 \mathrm{~d} 57 \&$ node $=14: 3 \cdot 0 \cdot 1 \cdot 2 \cdot 19 \& \operatorname{rgn}=\operatorname{div} 5$

Ross Stephenson is an assistant professor of aeronautics at Jacksonville University where he teaches courses in aviation management. Prior to becoming a professor, Stephenson was a program operations manager for L-3 Communications as well as a pilot with L-3 and Avenge, Inc. His background also includes many positions in the United States Marine Corps where he served as a master instructor, executive officer, operations manager, director of flight operations, and director of aviation safety and standardization. Ross is currently a PhD candidate at Embry Riddle Aeronautical University in the aviation program with an emphasis in aviation operations.

David Carroll is currently a PhD candidate in Embry-Riddle Aeronautical University's aviation program with an emphasis in safety and human factors. He retired from the US Air Force with 25 years of experience as a fighter pilot and instructor pilot, as well as numerous staff and leadership positions. Following his military service, he was director of training programs for Aviation Performance Solutions in Mesa, Arizona, providing on-aircraft, simulator, and integrated Upset Prevention and Recovery Training. He completed a bachelor of applied studies in aviation leadership and management from the University of Minnesota, and a master of aeronautical science with an operations specialization from Embry-Riddle Aeronautical University. His FAA certificates include an Airline Transport Pilot certificate with a B-737 type rating, and an Airframe \& Powerplant Mechanic certificate, in addition to several flight and ground instructor ratings. He is one of a handful of flight instructors worldwide currently accredited as a Master CFI-Aerobatics. 